\title{
SUITABILITY OF EXISTING TRAFFIC CALMING MEASURES FOR USE ON SOME HIGHWAYS IN
} EGYPT

\author{
Hamdy Faheem, $\mathrm{PhD}$ \\ Assistant Professor, Civil Engineering Department, Faculty of Engineering, Minia University, Minia 61111, \\ Egypt, e-mail: drhamdyfaheem@gmail.com
}

Submitted to the 9th International Conference on Civil and Architecture Engineering, May 29-31, 2012,

Cairo, Egypt

ICCAE-9

\begin{abstract}
The most common traffic calming measures on roadway network in Egypt are speed humps and cat-eye reflectors; the second one was investigated in previous study and found ineffective as traffic calming device on highways. This research examines the suitability of the existing speed humps on a major highway in Egypt for use, Cairo-Aswan agricultural highway was selected for this study, it is two-way two-lane highway, $140 \mathrm{~km}$ of it passing through Minia governorate and the posted speed limit is $90 \mathrm{~km} / \mathrm{h}$ reduced to $60 \mathrm{~km} / \mathrm{h}$ at dwelling zones. More than 150 speed humps exist on this highway in Minia region, located at intersections and entrance of towns and villages existing around that highway. Field measurements of speed, speed humps geometry, distance between humps, and in-depth interviews with different driver groups were used to assess the suitability of existing speed humps for use. The results show that most of speed humps are too high and some of them reach $25 \mathrm{~cm}$ height, low ground clearance vehicle' drivers complain that they cannot traverse without maneuvering speed humps, all drivers complain from rarity of signage, painting, and precautions which indicates the presence of speed humps, that led to traffic safety problems. Due to speed humps geometry, density of speed humps, and volume of traffic, much of delay and fuel consumption as well as damage of vehicles parts happen. The findings indicate that existing traffic calming measures are unsuitable for use in this class of highway.
\end{abstract}

Keywords: Road Safety, Speed humps, Transverse cat-eyes, Traffic calming measures

\section{INTRODUCTION AND BACKGROUND}

The Institute of Transportation Engineers (ITE) developed a standard definition of traffic calming in 1997: Traffic calming is the combination of mainly physical measures that reduce the negative effects of motor vehicle use, alter driver behavior, and improve conditions for non-motorized street users (Ewing, 1999). Traffic calming measures are intended to be self-enforcing. Second, as defined by the ITE subcommittee, traffic calming measures rely on the laws of physics rather than human psychology to slow down traffic.

Traffic calming had its genesis in The Netherlands Schlabbach (1997). A road hump with an elevation of 8 cm (3.1 in), installed at the end of an alley in Delft in 1970, was the first traffic calming fixture. By 1976, regulations that incorporated traffic calming features into design standards had been established. The success of the speed inhibiting measures used in the Netherlands led other European countries to experiment with these devices. Germany began experimenting with narrowings, roundabouts, and textured surfaces around 1977 (Schlabbach, 1997; Ewing, 2000). Similar traffic calming programs were developed in Norway, Sweden, Switzerland, England, France, Austria, Israel, and Japan Ewing (1999). Brindle (1997) reported that traffic calming concepts were borne in Great Britain during the 1960s; piecemeal and "patchy" applications followed there and in Australia during the 1960s and 1970s. Atkins (1999) suggested that traffic calming techniques had been used in a few U.S. cities since late 1940s. The use of vertical raisings of the road pavement as a passive method for controlling the speed of vehicles has become common in many countries. To date, several types of these devices have been introduced following the same basic principles, but with different levels of effectiveness and level of comfort.

The main aim of traffic calming devices is to decrease speeds used by drivers to the degree that they do not exceed acceptable speed levels. The slowing down effect of the calming devices is based on their detrimental 
effect on the driving comfort when the speed of the vehicle exceeds the desired level. Single calming devices or devices placed too far apart are only effective at one point. If a single speed hump is to be implemented, the warrants to be adopted on the motivation for the speed hump, either a hazardous location or a pedestrian/vehicle conflict, and speed is a common domining factor contributing to the cause of the accidents. The best traffic calming solution is the one that reduces speeds over the entire stretch of the road. Traffic calming is commonly applied in urban and residential road safety management and in the road safety management of through routes in towns and villages.

Many rural communities have developed around highways or major roads; as a result, the main street through these communities is often part of a high speed rural highway. In rural highway sections, the drivers maintain high operating speeds and generally they do not adequately reduce speeds when passing through small urban areas (DfT, 2005; NRA, 2005). Frequently, the transition from the rural to urban environments relies only on the posted speed limit, and this condition is totally inadequate to induce appropriate behaviors. For many years it was thought that speed could be reduced in transition zones by the posting of area speed limits, however the posting of a speed limit alone without any physical speed reducing measure did not result in any significant reduction in speed Van Schagen (2003).

Traffic calming devices included pre-warnings, gates, narrowings, humps and tables, raised areas, staggering, roundabouts, chicanes, islands, cushions, landscaping and plantings, and pavement textures and colors. "In all countries the use of these devices produced the desired speed reductions.

The National Road Association of Ireland (NRA 2005) produced a set of guidelines for the use of trafficcalming devices in towns along national routes, particularly in the high speed transition zone into a community. The Department for Transport (UK) also provides a set of guidelines for traffic calming on major roads through villages. The guide discusses techniques such as road narrowing and pavement markings (DFT 2005).

The analysis of drivers' response to installation of such raisings shows that users prefer larger humps since they are more comfortable in terms of jolts perceived inside the car, (Watts, 1973; Hodge, 1993; Webster and Layfield, 1998).

The influence of traffic calming measures on driver's behaviour can be considered exhausted at a distance more than 100 m before or after the device (Mak, 1986; City of Portland and Bureau of Traffic Management, 1998) and that distance will be decreased to about $50 \mathrm{~m}$ in case of low speeds (local streets) (Faheem, 2011). It was found that, on average, all types of speed management schemes reduced accidents. Schemes with vertical deflections offered the largest and most consistent percentage accident reductions (County Surveyors Society, 1994).

Traffic calming devices, such as speed humps, speed bumps, speed tables, roundabout, transverse rumble strips, optical speed bars, textured pavement, and cat-eye reflectors are spreading across Egypt; with the first and last devices being the most common (Faheem, 2011).

\section{PURPOSE OF THE STUDY}

The most common traffic calming measures on roadway network in Egypt are speed humps and cat-eye reflectors. Cat-eye reflectors was investigated in previous study and found ineffective as traffic calming device on highways (Faheem, 2011). This research examines the suitability of the existing speed humps on Cairo-Aswan agricultural highway for use. Cairo-Aswan agricultural highway is two-way two-lane main highway, the cross section of that highway is $12 \mathrm{~m}$ paved section $(7.5 \mathrm{~m}$ lanes width and $2.25 \mathrm{~m}$ average shoulder width each side), $140 \mathrm{~km}$ of it passing through Minia governorate with posted speed limit of 90 $\mathrm{km} / \mathrm{h}$ reduced to $60 \mathrm{~km} / \mathrm{h}$ at dwelling zones. More than 150 speed humps exist on that highway in Minia region only, located at intersections and entrance of towns and villages existing around that highway. Field measurements of speed, speed humps geometry, distance between humps, and in-depth interviews with different driver groups were used to assess the suitability of existing speed humps for use.

\section{VERTICAL-DEFLECTION TRAFFIC CALMING DEVICES}

Vertical speed control measures include speed humps, speed bumps, speed tables, and raised intersections, (Ewing, 1999). Speed humps are raised devices, parabolic in shape, placed across the road to slow traffic. They introduce a vertical acceleration factor to the vehicle. Speed humps are a very effective means of 
calming traffic. The most common design is the Watts Profile or circular hump. Most vehicles can traverse them safely at 25 to $30 \mathrm{~km} / \mathrm{h}$. Speed humps are designed to create a rocking motion that increases driver discomfort as crossing speed increases.

Generally, speed humps are 3.7 to $4.25 \mathrm{~m}$ in length and span the width of the road. On an exception basis, humps may be shorter or longer than the typical design. The length and height of the speed humps determine the speed at which traffic will travel over the devices. Shorter lengths and greater heights slow cars most drastically. Not to be confused with a speed hump, a speed "bump "is a raised area commonly used in parking lots and on some private roadways, are generally from $7.5-15.0 \mathrm{~cm}$ in height with a length of 0.30 to $0.90 \mathrm{~m}$ in the direction of travel (Ewing, 1999; ITE Traffic Engineering Council, 1997).

Speed tables are essentially flat-topped speed humps and are sometimes referred to as "Seminole County speed humps" or "trapezoidal speed humps". Speed tables also are often used at pedestrian crossings and may be referred to as a raised crosswalk (Ewing, 1999). Speed tables have gently sloped ramps on both ends, which allow slightly higher vehicle speeds and a smoother transition than speed humps (ITE, 2007). When designed to the typical dimensions, speed tables have an 85th-percentile speed of 25 to $30 \mathrm{mph}$, (ITE, 1999). A plateau is an alternative speed table design that has been used in the Netherlands and installed on facilities with speeds ranging from 35 to $50 \mathrm{mph}$ (Schermers and van Vliet, 2001).

Speed humps are generally supported by the public (Ewing, 1999; Clement, 1983; Gorman et al., 1989). To achieve particular crossing speeds, humps may range from two to four inches high. Less than two inches produces little speed reduction, and more than four inches greatly increases the risk of vehicle grounding.

While traffic calming measures reduce vehicle speeds on neighborhood streets and may contribute to enhanced road safety, these measures can result in significantly higher fuel consumption and emission rates when drivers accelerate aggressively (Ahn and Rakha 2009). They also caused serious damage to vehicles if constructed too high. Overseas research has indicated that the ideal speed hump for local roads should be approxinately $3.7 \mathrm{~m}$ in length and between 70 and $120 \mathrm{~mm}$ in height. If shorter, they are too severe and if longer they are more easily negotiable by typical passenger cars. Ground clearnce of different vehicles should be considered to avoid the bottom of the the vehile scrapping on the hump.

Rakha and Ding (2003) concluded that the vehicle fuel consumption and emission level depends on the conditions under which the vehicle operates. The changes in the vehicle fuel consumption and the emission rates are mostly associated with changes in the vehicle cruise speed and the driver acceleration aggressiveness.

\section{INFLUENCE OF SPEED AS A FACTOR IN ACCIDENTS AND INJURY}

Speed is at the core of the road accident problem because the higher the speed, the shorter the time available to avoid collision, and the more severe the impact when collision occurs. Excess speed is defined as exceeding the relevant speed limit, whereas inappropriate speed is defined as driving at a speed unsuitable for the prevailing road and traffic conditions. This distinction is important because a speed limit only declares higher speeds to be illegal, and it remains for each driver to decide what speed, within the limit, is appropriate.

The contribution of speed lies in the fact that, given a particular set of circumstances, an accident might be avoided (or its consequences might be less severe) if drivers' speeds had been lower (Stone, 2004). Traffic calming devices has been found to be particularly effective at reducing vehicle speeds, and thus the frequency and severity of accidents. Several studies have demonstrated a clear relationship between speed and accidents (Finch, Kompfner, Lockwood and Maycock, 1994). The Oregon DOT reported speed statistics indicating that there is an $85 \%$ likelihood of death for a pedestrian struck at $40 \mathrm{mph}$. One struck at $30 \mathrm{mph}$ has a $45 \%$ chance of being killed, and the risk drops to $15 \%$ if the pedestrian is struck at $20 \mathrm{mph}$ (ODOT 1999). Accident analysis shows that the higher the impact speed, the greater the likelihood of serious and fatal injury. For car occupants in accidents with impact speeds of $50 \mathrm{miles} / \mathrm{h}$ the likelihood of death is 20 times that of an impact speed of 20 miles/h (IIHS, 1987).

Excessive speed is a major problem within roadwork sites. When drivers do not adequately adapt their speed to these conditions, they increase their risk of accident involvement. Indeed, excessive speed is currently a primary contributory factor in roadwork-related accidents around the world (Australia Department of Infrastructure, Transport, Regional Development and Local Government, 2009; New Zealand Ministry of 
Transport, 2009; United Kingdom Department for Transport, 2009). In addition to the impact on human lives, speeding, particularly during non-work hours, often damages roadwork machinery, signage and the road surface, necessitating otherwise unnecessary road repairs and prolonged job completion times (Miller, 2005). Lower speeds provide drivers more time to react and be aware of their surroundings. Lower speeds also reduce the likelihood and severity of vehicle crashes. The National Highway Traffic Safety Administration (NHTSA) estimates that the probability of death, disfigurement, or debilitating injury doubles for every 10 mph over 50 mph (NHTSA 2005a). The Federal Highway Administration estimates that each one mile per hour reduction in speed may reduce injury crashes by five percent (TRB 2002). Burrington et al. (1998) indicated that traffic calming may also discourage crime in a community.

Furthermore, fatal or serious injury accidents are significantly reduced when traffic calming measures are implemented (Webster, 1993; Webster and Mackie, 1996). However, frequent acceleration and deceleration maneuvers caused by the traffic calming measures may yield higher vehicle emissions and extra energy consumption on neighborhood streets.

\section{SPEED HUMP GEOMETRIC DESIGN}

Several researchers have proposed speed hump geometric design standards, and have attempted to optimize hump size, shape, and height as a function of the response characteristics of motor vehicles (e.g., Fwa and Tan, 1992; Granlund, 2003; Pedersen, 1998; Weber and Braaksma, 2000).

The height of semi-circular speed hump is determined by the maximum desired speed at which normal passenger cars can comfortably negotiate the measure; for example the height of the semi-circular hump of 120,100 , and $80 \mathrm{~mm}$ is suitable for desired maximum speed over typical speed hump of 30,40 , and $50 \mathrm{~km} / \mathrm{h}$ respectively (National Guideline of Traffic Calming, 1969).

In 1993, ITE developed "Guidelines for the Design and Application of Speed Humps" (ITE Traffic Engineering Council, 1997). These design guidelines are based on a 12-foot Watts style speed hump. Despite these guidelines, a number of speed hump designs are used (Ewing, 1999).

In 1975, the Transport and Road Research Board of Great Britain determined that the ideal design shape for a speed hump was parabolic, 12 feet wide in the direction of travel, and four inches high (Clement, 1983). In the United States, the design guidelines developed by ITE were based on the Watts speed hump profile (ITE Traffic Engineering Council, 1997). These guidelines suggested that a parabolic shape, 12 feet long, with a height of three to four inches be used. Experience in the United States since 1993 has resulted primarily in the use of 3.5-inch speed humps. This design typically results in an 85th percentile speed between 15 and 20 mph (Ewing, 1999). The Watts style hump, however, has been modified in several jurisdictions. For example, Portland, Oregon, has developed a 14-foot parabolic speed hump that is three inches in height. The 85th percentile speed for the 14-foot parabolic speed hump is about $3 \mathrm{mph}$ higher than the standard 12-foot Watts hump (Ewing, 1999).

Crossing speed is a function of the cross-sectional area of a hump relative to its length (Fwa and Tan, 1992). The greater the ratio of cross-sectional area to length, the lower the design speed. A parabolic hump of the same height and length as a circular hump, for example, will have a slightly lower crossing speed. Crossing speeds naturally vary by type of vehicle and status.

For vertical curves, AASHTO does not provide a comparable definition but states that "riding is comfortable on sag vertical curves when the centrifugal acceleration does not exceed $1 \mathrm{ft} / \mathrm{sec} 2$. A greater degree of vertical acceleration is tolerable on crest vertical curves (rises) than on sag vertical curves (dips) because gravitational and centrifugal forces oppose one another on crests and combine with one another on sags. The international traffic calming literature suggests that vertical acceleration of up to $1 \mathrm{~g}$, or $32 \mathrm{ft} / \mathrm{sec} 2$, is tolerable for short periods, but this much force may seem excessive on its face. So the answer may lie somewhere between these extremes (Hodge, 1993). The average of $0.7 \mathrm{~g}$ usually used to model discomfort in other speed-hump studies (Watts, 1973; Fwa and Liaw, 1992; Weber and Braaksma, 2000).

Road humps need to be carefully built to specification as earlier work has shown that quite small deviations can adversely affect the comfort of vehicle occupants. This is particularly true of the profile at the transition from road to hump. 


\subsection{Speed Estimates}

For speed humps that are approximately circular in shape, crossing speeds can be estimated with the formula from ITE's Traffic Calming State-of-the-Practice. The rate of centrifugal acceleration is defined as:

$\mathrm{A}=2.15 \mathrm{~V}^{2} / \mathrm{R}$

where $A$ is acceleration (in $\mathrm{ft} / \mathrm{sec}^{2}$ ), $\mathrm{R}$ is the radius of a vertical curve in feet and $\mathrm{V}$ is the velocity at which the curve is traversed in mph.

The formula was derived using the common 12-foot hump as a reference point. Whatever forces of centrifugal acceleration are tolerable going over this hump at its 85th percentile speed, will be equally tolerable going over other vertical measures at their 85th percentile speeds. Such a hump has an 85-percentile crossing speed of $19 \mathrm{mph}$.

Substituting these values into the preceding equation, the assumed tolerable rate of centrifugal acceleration crossing a 12-foot hump is calculated to be on the order of $12.5 \mathrm{ft} / \mathrm{sec}^{2}$, which is equivalent to $0.4 \mathrm{~g}$. Substituting this value for $\mathrm{A}$ in the above equation and solving for $\mathrm{R}$, the resulting formula represents an approximation of the relationship between 85th percentile travel speed and the radius of any measure of approximately circular shape:

$\mathrm{V}=2.41(\mathrm{R})^{1 / 2}$

The more the profile of a hump deviates from a purely circular shape, the less applicable the above equation will be. A method of adjusting for deviations from a purely circular shape is suggested by T.F. Fwa and C.Y. Liaw, 1992. Using precise hump measurements and corresponding speed data, Fwa and Liaw found that crossing speeds depended more on the shape of the hump than on the height-to-length ratio. Two humps with the same height and length can have very different crossing speeds if one's profile is more rounded and the other is more triangular shaped. For every ten percent increase in the ratio of cross sectional area to length, the 85th percentile crossing speed dropped by five percent. This relationship can be used to predict crossing speeds for alternative hump profiles relative to circular humps.

\section{DESCRIPTION OF EXISTING SPEED HUMPS}

There are traffic calming devices in most of Egyptian roadway network, they have different types and shapes, most of these traffic calming devices affect on traffic operation and safety. Speed humps are the most common traffic calming devices. Generally the construction of speed humps may divide as follows: some of speed humps construct under the responsibilities of the General Authority for Roads, Bridges, and Land Transport (GARBLT)-Ministry of transport and it is mainly for main highways. Ministry of local development, road directorate-paving units is in charge of the construction of speed humps for all Provincial roads and local roads; however, they construct speed humps on highways using the typical speed hump specified for local roads based on requests from local residents after accidents on highways (political purpose), the associated warning signs and marking for the constructed humps by road directorate is the responsibility of GARBLT on highways. Therefore, after the construction of speed humps in many locations until supporting the warning signs and markings for road users at these sites, many traffic safety problems happen. Figure 1 shows the typical cross section of the speed hump that the road directorate constructs everywhere. The last part of speed humps may construct by normal people, for example after road accidents you may find new speed humps constructed suddenly without supporting signs and markings for road users and without any specifications (random), the last one is the most dangerous.

Cairo-Aswan agricultural highway connects Cairo with Upper Egypt reaching to Aswan governorate, total length of it is about one thousand kilometer, and the average traffic volume on this section of the highway is about 7000 vehicles / day according to 2011 data from the General Authority for Roads, Bridges, and Land Transport. This highway passing through many built up areas; parallel to it there is Ibrahimia canal. All intersections are at grade and there are $46 \mathrm{~T}$ - intersections as a result of the existing canal. Minia governorate starts to use speed humps and cat eye refractors as traffic calming measures about four years ago since 2007. The use of speed humps growing up with high rate as follows: two field surveys were carried out, the first survey was in august 2009 and found that there are 77 transverse cat-eyes reflectors groups (as traffic calming measures) and 52 speed humps over a length of $140 \mathrm{~km}$ of that highway passing through Minia 
governorate. The aims of that survey were to obtain the distribution of the traffic calming measures, the cross section profile of the speed humps, and the warning signs and marking that available before and at the humps. The results of the first field survey show that the minimum distance between humps was 100 meters and the maximum distance was $26.7 \mathrm{~km}$, the short distance between speed humps is as a result of there is two speed humps around each intersection because of the geometry of that highway (two-way two-lane), the length of the speed humps vary from 1.50 meter to 5.0 meters and the height of them vary from $9 \mathrm{~cm}$ to $25 \mathrm{~cm}$. For the available precautions around the humps there is few, such as there is traces of painting but not at all humps, there is movable steel barrier painted with reflective painting over some humps, some reflective sign posts at distances from 50 to 100 meters before the humps, and at some locations there is flashing light. Figure 2 shows the distribution of the speed humps over the $140 \mathrm{~km}$ distance from the first survey.

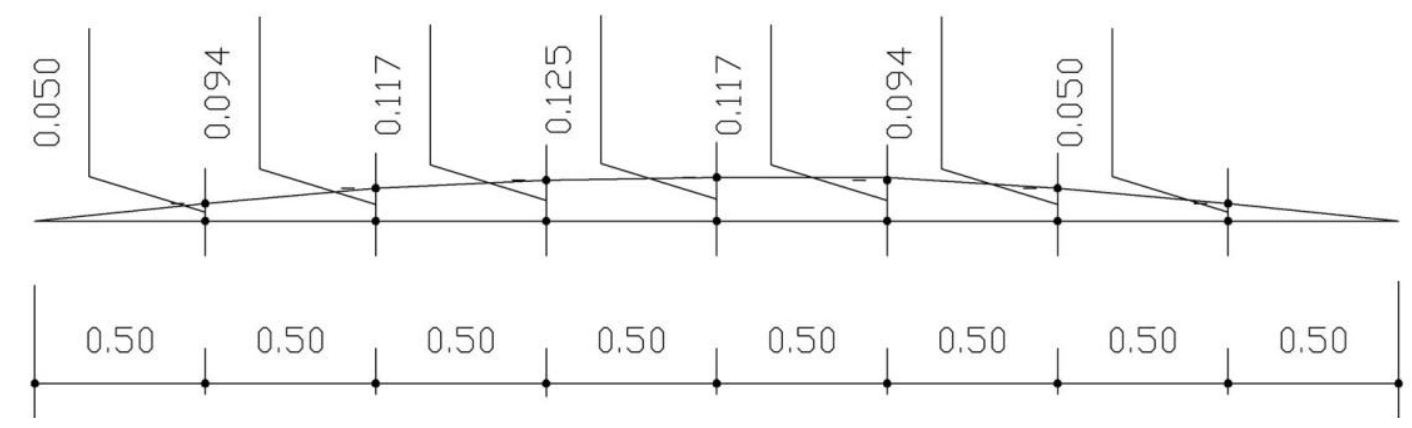

Figure 1 shows the typical cross section of the speed hump that road directorate constructs everywhere.

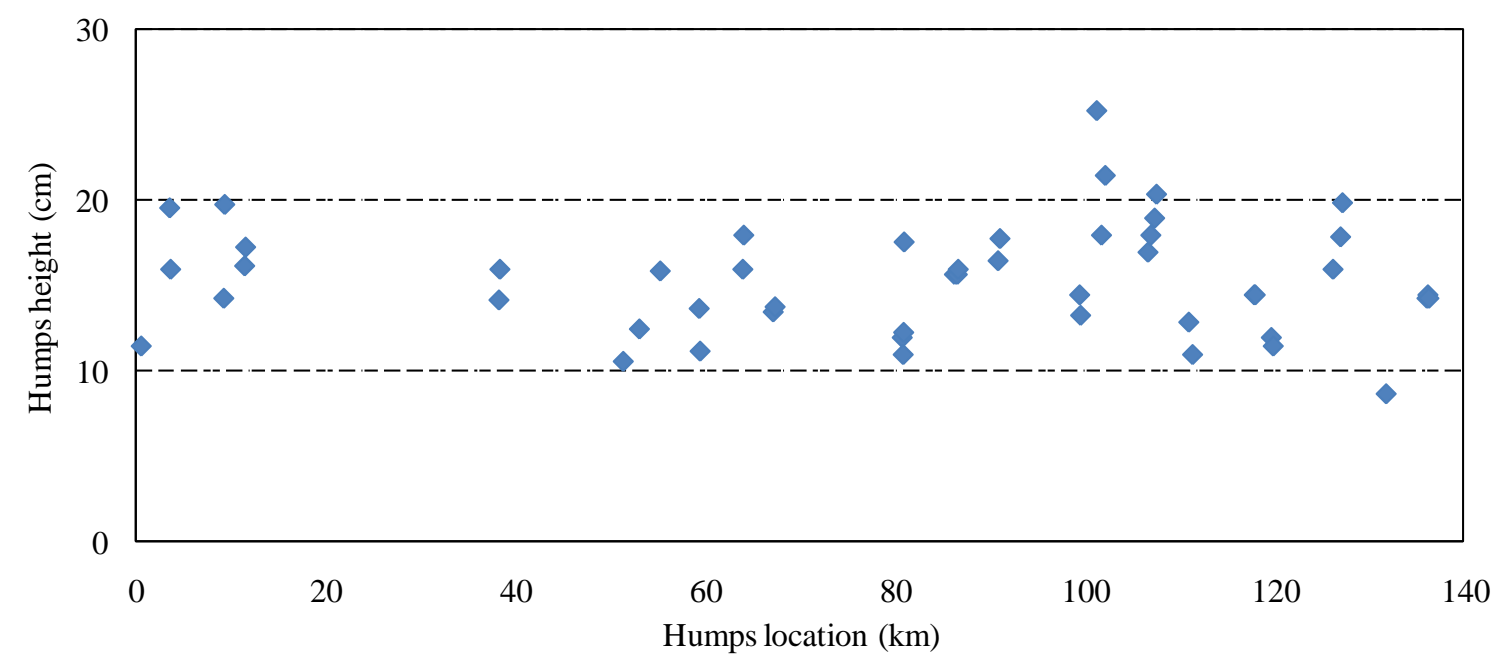

Figure 2 shows the distribution of the speed humps over the $140 \mathrm{~km}$ distance from the first survey

The second survey was carried out in August 2011 after about two years from the first survey, with the same objectives as before, the results of the second survey show that no increase in transverse cat-eyes reflectors groups, the number of speed humps became 151 and the minimum distance between humps was 50 meters and the maximum distance decreased to $5.4 \mathrm{~km}$, the length of the new speed humps vary from 2.5 meter to 4.5 meters and humps height for the new constructed speed humps vary also between $10 \mathrm{~cm}$ to $20 \mathrm{~cm}$, and the available precautions is the same as before at the humps. Figure 3 shows the cross section profiles of some existing speed humps. From figure 2 it is obvious that no consistency in cross section of the speed humps as they construct the speed humps manually and they don't follow the specifications of the typical 
speed hump. Figure 4 shows the distribution of the speed humps over the $140 \mathrm{~km}$ distance from the second survey.
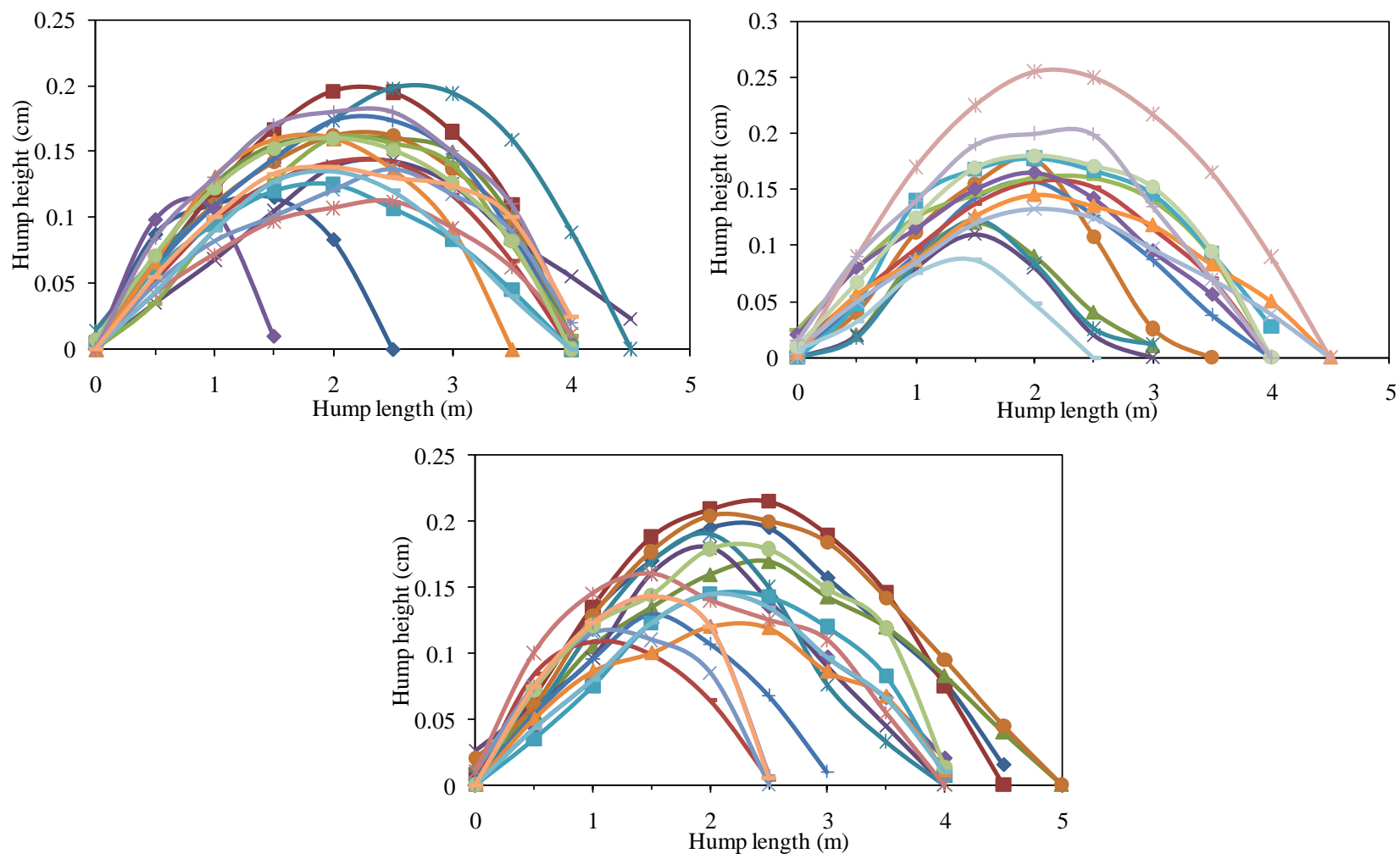

Figure 3 shows the cross section profiles of some existing humps

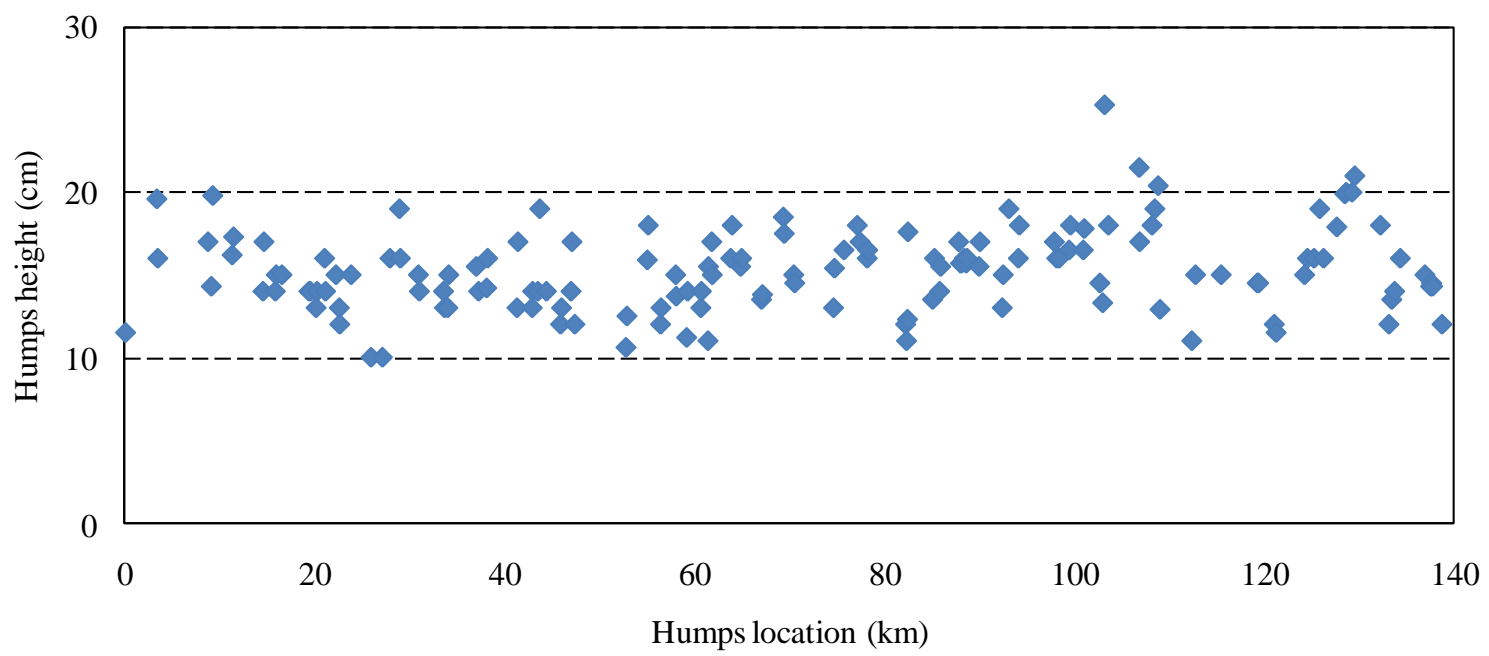

Figure 4 shows the distribution of the speed humps over the $140 \mathrm{~km}$ distance from the second survey

\section{STUDY LOCATIONS AND SPEED MEASUREMENTS}

Three speed humps locations were selected in this study. All test sites were located on Cairo-Aswan agricultural highway that runs north/south direction. These locations were selected on straight sections to minimize the influence of geometric features of the highway. The first location was on the southbound 
approach (from Cairo to Aswan) and the second and third locations were on the northbound approach (from Aswan to Cairo).

In selecting the test sites, the following parameters were considered: for the first location the hump length was $4 \mathrm{~m}$ and its height was $20 \mathrm{~cm}$, and the distance between the 2 speed humps was $100 \mathrm{~m}$, for the second site the hump length was $4 \mathrm{~m}$ and its height was $17 \mathrm{~cm}$, and the distance between the 2 humps was $50 \mathrm{~m}$, for the third site the hump length was $3 \mathrm{~m}$ and its height was $13 \mathrm{~cm}$, and the distance between the 2 humps was $100 \mathrm{~m}$.

To evaluate the effect of the existing speed humps, the speed profile of the traffic stream was obtained; data were collected using Digital video cameras. Data were collected upstream and downstream of three speed humps location. To determine vehicle speed from recorded videos, transverse white lines were painted across the span of the lanes on the roadway surface every 10 meters for 100 meters upstream and downstream from the device. Vehicle speeds were calculated by dividing the distance between any 2 lines (10-meter) over the elapsed time, which can be determined from the videos with a high degree of accuracy. At each study location, a minimum sample size of 200 vehicles was used. This sample size was assumed to be adequate to determine the speed profiles at the study locations. From field observation, it was noticed that most of drivers start to reduce the speed approximately 70-100 meters or less upstream of speed hump location. The most effective distance in speed reduction was the last 50 meters just upstream of the device. The speeds measured are typically spot speeds. Average speed and the $85^{\text {th }}$ percentile speed are the two metrics used in this study to evaluate the effect of traffic-calming measures. Running speed is considered normal 100 meter both upstream and downstream of the speed hump(s).

\section{IN-DEPTH INTERVIEWS RESULTS}

In addition to the field measurements, in-depth interviews with different drivers were performed. A total of 120 drivers were surveyed during 2011. The results of the survey can be summarized as follows:

1- The speed humps are too much and there is no consistency in humps geometry that causes excessive discomfort for vehicles occupants and aggressive driving.

2- Some drivers fail to slow down their speed because there are no or few visual indications to inform the driver that there are speed hump in front of them and that cause traffic safety problems.

3- No proper signage and markings, the signing and marking of road humps are essential to ensure their visibility, especially at night, and to warn drivers to slow down in good time for them, and some speed humps are constructed at unsuitable locations.

4- Low ground clearance vehicles traverse the speed humps hardly because of its over-heights. Some motorists drive with their wheels in road shoulder in order to minimize the impact of the humps, some drivers maneuver around the humps and traverse it diagonally.

5- Speed humps caused increase of fuel consumption by about 20-40\% due to increased slowing and braking. Also, it increased travel time and delay because of the geometry of the speed humps and the short distance between speed humps and the huge number of speed humps. Trip time increase by about 30-50\% that depends on vehicles types, vehicle's loading condition, and travel distance.

6- Humps cause long term damage to vehicle components, especially the suspension system, and they cause damage to the undersides of vehicles with low ground clearance, increased wear and tear to brakes and suspensions system which increase maintenance costs.

7- Drivers prefer low and long speed hump because they can traverse it with relatively high speed and will not cause large damage to their vehicles if they don't notice it from long distance. And also they prefer flashing light as a warning before speed humps.

\section{RESULTS AND DISCUSSION}

From field observations, the existing speed humps have been shown to be effective at reducing speeds in the vicinity of the device. However, the reduction in speed is too much, which cause delay and increasing fuel consumption. Also as a result of existing huge amount of speed humps, inconsistency of hump geometry, over-heights of speed hump, and reality of markings and signage all these factors cause traffic safety problems, damage of vehicles and increasing of maintenance cost. This research was performed to evaluate the suitability of the existing speed humps for use by measuring how drivers react to the devices in terms of 
how vehicles speeds changes with respect to the location of the device. Mean speeds were compared at all locations along a distance of 90 meters around the device(s) (most of speed humps existing as a pairs because of the large number of T-intersections and the type of the highway (two-way two-lane). Speed data was analyzed upstream of the device, at the location of the device, and downstream of the device.

Figure 5 shows the results of the first location test site, mean and 85th Percentile speed for Cairo-Aswan agricultural highway southbound direction. In addition, the change in the average mean speed with respect to normal flow speed as a function of the distance from the device is shown in figures 5 .

A comparison between the speed at the first hump, mid-way between humps, and the second hump, and the normal speed, shows that the reduction in speed was larger than the required reduction in case of using such devices. The mean speed was reduced from $59.89 \mathrm{~km} / \mathrm{h}$ to $11.58 \mathrm{~km} / \mathrm{h}, 27.50 \mathrm{~km} / \mathrm{h}$, and $12.18 \mathrm{~km} / \mathrm{h}$ or if it is considered the normal speed equal 100 percent it reduced to $19.33 \%, 45.91 \%$, and $20.33 \%$ respectively. For the 85 th percentile speed it was reduced from $68.16 \mathrm{~km} / \mathrm{h}$ to $14.25 \mathrm{~km} / \mathrm{h}, 32.70 \mathrm{~km} / \mathrm{h}$, and $13.81 \mathrm{~km} / \mathrm{h}$ or it reduced to $20.9 \%, 48.0 \%$, and $20.26 \%$ respectively.
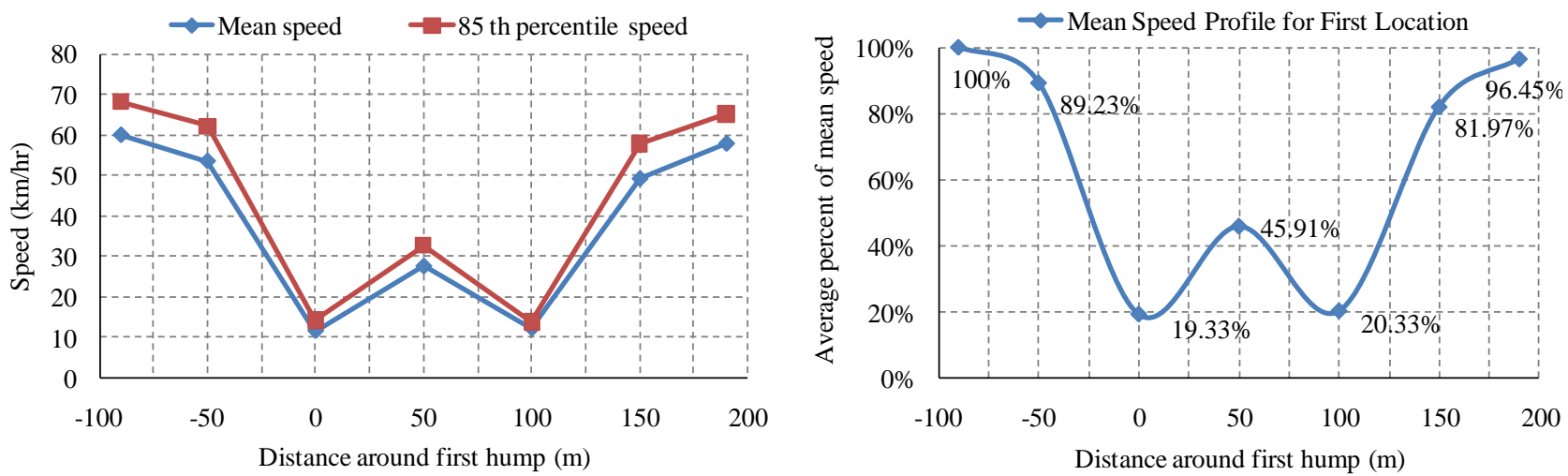

Figure 5 Mean, 85th Percentile speed, and the change in the average mean speed for first location test site
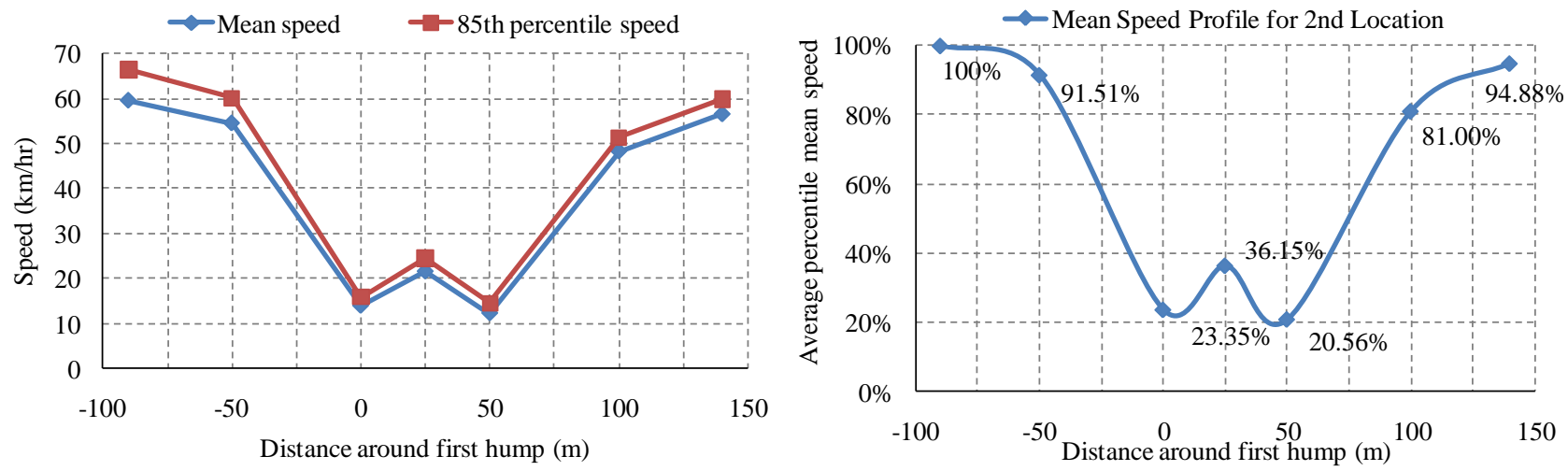

Figure 6 Mean, 85th Percentile speed, and the change in the average mean speed for $2^{\text {nd }}$ location test site

Figure 6 shows the results for second location test site, Mean and 85th Percentile speed for Cairo-Aswan agricultural highway northbound direction In addition, the change in the average mean speed with respect to normal flow speed as a function of the distance from the device is shown in figure 6 .

A comparison between the speed at the first hump, mid-way between humps, and the second hump, and the free flow speed, shows that the reduction in speed was larger than the required reduction in the cases of using such devices. The mean speed was reduced from $59.51 \mathrm{~km} / \mathrm{h}$ to $13.9 \mathrm{~km} / \mathrm{h}, 21.52 \mathrm{~km} / \mathrm{h}$, and $12.24 \mathrm{~km} / \mathrm{h}$ or it reduced to $23.35 \%, 36.51 \%$, and $20.56 \%$ respectively. For the 85 th percentile speed it was reduced from $66.46 \mathrm{~km} / \mathrm{h}$ to $15.87 \mathrm{~km} / \mathrm{h}, 24.45 \mathrm{~km} / \mathrm{h}$, and $14.47 \mathrm{~km} / \mathrm{h}$ or it reduced to $23.88 \%, 36.79 \%$, and $21.77 \%$ respectively. 
Figure 7 shows the results for first location test site, Mean and 85th Percentile speed for Cairo-Aswan agricultural highway northbound direction In addition, the change in the average mean speed with respect to normal flow speed as a function of the distance from the device is shown in Figures 7.

A comparison between the speed at the first hump, mid-way between humps, and the second hump, and the free flow speed, shows that the reduction in speed was larger than the required reduction in the cases of using such devices. The mean speed was reduced from $62.73 \mathrm{~km} / \mathrm{h}$ to $15.37 \mathrm{~km} / \mathrm{h}, 31.12 \mathrm{~km} / \mathrm{h}$, and $14.45 \mathrm{~km} / \mathrm{h}$ or it reduced to $24.49 \%, 49.6 \%$, and $23.03 \%$ respectively. For the 85 th percentile speed it was reduced from 70.63 $\mathrm{km} / \mathrm{h}$ to $17.65 \mathrm{~km} / \mathrm{h}, 34.13 \mathrm{~km} / \mathrm{h}$, and $16.63 \mathrm{~km} / \mathrm{h}$ or it reduced to $25.0 \%, 48.32 \%$, and $23.35 \%$ respectively.
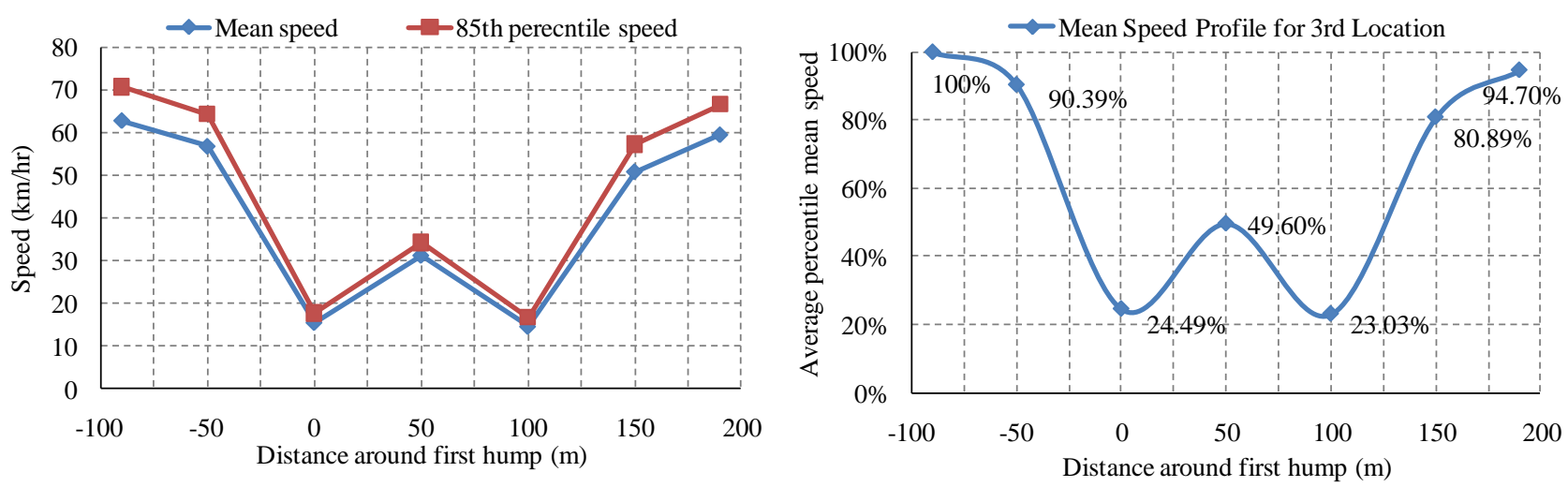

Figure 7 Mean, 85th Percentile speed, and the change in the average mean speed for $3^{\text {rd }}$ location test site

From field observations, it was noticed that, some motorists approaching speed humps slow down sharply, probably as a result of the huge number of speed humps and the over-heights of speed humps or as a result of they don't notice the speed hump from long distance or to minimize/compensate the delay in the journey time. Other motorists reduce the speed fairly uniformly until the device is reached. Results show that the effect of the speed humps can be considered quite local, which means that speed reduction is concentrated in a short distance of about 50-100 m upstream and downstream of the device, and between the two humps that means that the influence zone in case of double humps system is about at least $200 \mathrm{~m}$, that cause much of delay in such class of highway. Previous studies (Mak, 1986; City of Portland and Bureau of Traffic Management, 1998; Barbosa et al., 2000) have shown that speed should decrease and reach its minimum value at the device location, then increase to original values. The spatial range in which the speed decreases represents the influence zone of the undulation. The results from the three sites showed that once the vehicles had crossed the device, drivers tended to increase their speed quickly to reach their initial speed levels within a short distance. This observation confirms the existence of an influence region ranging from 50 to $100 \mathrm{~m}$.

By applying the above formula to calculate the $85^{\text {th }}$ percentile crossing speed of the existing speed humps, it is found that the obtained $85^{\text {th }}$ percentile speed from the above formula is higher than the actual speed (for example, 14.25 instead of $22 \mathrm{~km} / \mathrm{hr}, 15.87$ instead of $24 \mathrm{~km} / \mathrm{hr}, 17.65$ instead of $21 \mathrm{~km} / \mathrm{hr}$ ) that is may be because the excessive height of the speed humps which enforce low ground clearance car' drivers to traverse the speed hump diagonally with speed about $5 \mathrm{~km} / \mathrm{hr}$.

\section{REDUCTION IN SPEEDS}

Speed reduction is the primary purpose of speed humps. Review of the various studies indicates that the magnitude of speed reduction depends on a number of factors including the design and spacing, the surrounding environment, and vehicle mix. The effects of speed humps also vary as a function of speed limit and speed hump dimensions (height and width). Speed profiles were created to evaluate speeds as vehicles approached, traversed, and exited speed humps.

In all cases, speeds decreased. However, the changes in speed vary; this variation may be partly due to the lack of formal design standards and spacing requirements. Previous studies showed that for 12-foot speed 
humps, the changes in the 85 th percentile speeds varied from $+1 \mathrm{mph}$ to $-16 \mathrm{mph}$ [4 percent to -42 percent] (Ewing, 1999; Clement, 1983; Transportation Association of Canada, 1998).

The speed profiles showed that speed humps reduce speed in all sites. Crossing speed is the speed at which a vehicle traverses a speed hump, while the speed change is the difference between before and after speeds (Mak, 1986). It is clear that the crossing speed decreases and the speed change increases as the speed hump height increase, it can be also notice that the shorter the speed hump spacing the higher reduction in speed between humps.

Results show that the change of the 85th percentile speed and mean speed as a function of the distance from the device are over $75 \%$ reduction in all cases which considered not accepted from the view point of operation also the over-height of the humps is not accepted from the view point of safety.

\section{CONCLUSIONS AND RECOMMENDATIONS}

One of the main criteria of using speed humps is if the 85th percentile of measured vehicle speeds exceed the speed limit, and the function of the speed humps is to reduce the speed by about $5 \mathrm{~km} / \mathrm{hr}$ under the speed limit at the hump location, it is well known that the allowable speed is $90 \mathrm{~km} / \mathrm{hr}$ reduced to $60 \mathrm{~km} / \mathrm{hr}$ at dwelling zones on this highway, however, the used speed humps reduce the speed in all cases to less than 20 $\mathrm{km} / \mathrm{hr}$ which considered very high reduction on this class of highways. Speed humps caused excessive drop in speed at the humps, the drop in speed reaches an average of $75 \%$ of the normal speed.

As a result of the inconsistency in speed humps geometry, over-height, spreading of speed humps, lack of warning and precautions that indicate the presence of speed humps, all these factors led to delays, increase of fuel consumption "trip time increase by about 30-50\% and increase of fuel consumption by about 20$40 \%$ ", as well as traffic safety problem for road users. Speed humps cause long term damage to vehicle components which increase maintenance costs. Drivers prefer low and long speed hump and also they prefer flashing light as a warning before speed humps.

In designing a speed hump, the location and placement of the hump(s), the geometric shape and size of the speed hump(s), and the necessary signs and pavement markings all need to be considered. Selection of the suitable traffic calming measure depends on how much reduction of speed is needed.

It should be evaluate all constructed traffic calming devices and remove unsuitable devices and to forbidden random construction of traffic calming devices. It is recommended to use suitable type/s of traffic calming which have been approved and associated signs and marking.

The selection of the suitable calming device and its location should be made on the basis of engineering study. Finally based on the field measurement results and the interview with different drivers it could be concluded that the existing speed humps is unsuitable for use in this class of highway

\section{ACKNOWLEDGEMENTS}

Support for this study was provided by Faculty of Engineering, Minia University, Egypt, as a contribution to improve safety in Minia governorate. My great appreciation and thanks to Engineer Ayman, Mostafa, and Mr. Emad for helping in the field work and survey.

\section{REFERENCE S}

Atkins, C. (1999). "Traffic calming", Transportation planning handbook (2nd edition) Washington, DC" Institute of Transportation Engineers.

Ahn, K., Rakha, H. (2009). "A field evaluation case study of the environmental and energy impacts of traffic calming”, Transportation Research Part D 14 411-424.

Australia Department of Infrastructure (2009). "Transport, Regional Development and Local Government", Retrieved 29 June 2009, from research@infrastructure.gov.au.

Brindle, R. (1997). "Traffic calming in Australia - more than neighborhood traffic management", ITE Journal, 67(7), 26-33.

Barbosa, H., Tight, M.R., and May, A.D. (2000). "A model of speed profiles for traffic calmed roads", Transportation Research Part A 34, 103-123. 
Burrington, Stephen and Bennet Heart. (1998). "City Routes, City Rights, Conservation Law Foundation”, (Boston; www.clf.org).

IIHS (1987). "IIHS Facts: 55 speed limit", Arlington (VA): Insurance Institute for Highway Safety.

ITE Traffic Engineering Council Speed Humps Task Force (1997). "Guidelines for the Design and Application for Speed Humps", Institute of Transportation Engineers, Washington, D.C.

Institute of Transportation Engineers. (ITE, 1999). "Traffic Calming: State of the Practice", ITE/FHWA, Washington, D.C.

Institute of Transportation Engineers (ITE, 2007). "Traffic Calming for Communities", www.ite.org/traffic/table.htm (accessed August 2007).

Clement, John. (1983). "Speed Humps and the Thousand Oaks Experience”, ITE Journal, January, pp. 35-39. County Surveyors Society (1994).” Traffic Calming in Practice”, Landor Publishing Ltd., London.

City of Portland, Bureau of Traffic Management (1998). "City of Portland speed bump peer review", Portland, OR, USA.

DfT, Department for Transport (2005). “Traffic Calming on Major Roads”, UK. Oct 2005.

Ewing, R. (1999). "Traffic Calming State of Practice", Institute of transportation Engineers. Federal Highway Administration, U.S. Department of Transportation, Washington, D.C., August.

Ewing, R. (2000). "Traffic Calming Main Roads", Compendium of Papers for the 79th Annual Meeting of the Transportation Research Board (CD-ROM). Preprint for Transportation Research Board, National Research Council, Washington, D.C., January.

Fwa T.F., and Liaw C.Y. (1992). "A Rational Approach for Geometric Design of Speed-Control Road Humps", Washington, D.C., USA: Paper presented at the 71st Transportation Research Board Annual Meeting, January.

Fwa T.F., Tan L.S. (1992). “Geometric Characterization of Road Humps for Speed-Control Design”, Journal of Transportation Engineering, Vol. 118, July/August, pp. 593-598.

Finch, D.J., Kompfner, P., Lockwood, C.R., and Maycock, G. (1994). "Speed, speed limits and accidents", TRL Report 58. Crowthorne, UK: Transport Research Laboratory.

Faheem Hamdy, (2011). "Effectiveness of Using Cat-Eye Reflectors as Warning and Traffic Calming Devices in Local Roads and Highways", 3rd international conference on road safety and simulation, September 14-16, Indianapolis, USA.

Gorman, Michael N., Massoum Moussavi, and Patrick T. McCoy. (1989). "Evaluation of Speed Hump Program in the City of Omaha", ITE Journal, Vol. 59, June, pp 28-32.

Granlund, J. (2003). "Design of a shock-free speed hump", Proceedings, $10^{\text {th }}$ international congress on sound and vibration, Stockholm, Sweden, July 7 - 10 (pp. 2891-2898).

Hodge, A.R. (1993). "Speed control humps-A trial at TRL", Project Report 302. Transport Research Laboratory, UK.

Kassem, E., and Al-Nassar, Y. (1982). "Dynamic considerations of speed control humps", Transportation Research Part B 16, 291-302.

Lockwood, I. M. (1997). “ITE traffic calming definition”, ITE Journal, 67(7), 22-24.

Layfield, R.E., and Parry D.I. (1998). "Traffic calming-Speed cushion schemes”, TRL Report 312. Transport Research Laboratory, UK.

Mak, K.K. (1986). "A further note on undulation as a speed control device”, Transportation Research Record 1061, 13-20.

Miller, N. (2005). "Slow Down Around Roadworks Campaign", Retrieved 1 June 2007, from http://www.slowdown.co.nz/resources/news 08Mar20052.php.

National Guideline of Traffic Calming (1969). Pretoria: Dept of Transport. (COD Report, CR-96/036) 
NHTSA, (2005a). "Speed Shatters Life", National Highway Traffic Safety Association. http://www.nhtsa.dot.gov/people/outreach/safesobr/pub/think.pdf. Accessed November 2005.

NRA, National Roads Authority (2005). "Guidelines on Traffic Calming for Towns and Villages on National Routes", Dublin.

New Zealand Ministry of Transport (2009). "Crash Analysis System”, Ministry of Transport, Wellington, New Zealand.

Oregon Department of Transportation (ODOT) (1999). "Main Street...when a highway runs through it", A Handbook for Oregon Communities.

Pedersen, N. L. (1998). "Shape optimization of a vehicle speed control bump", Mechanics of Structures and Machines, 26(3), 319-342.

Pharaoh, T. M., and Russell, J. E. (1991). "Traffic calming policy and performance", The Netherlands, Denmark and Germany. Town Planning Review, 62(1), 79- 106.

Rakha, H., Ding, Y., (2003). "Impact of stops on vehicle fuel consumption and emission", Journal of Transportation Engineering 129, 23-32.

Sumner R., and Baguley C. (1979). "Speed Control Humps on Residential Roads", TRRL Laboratory Report 878. Transport and Road Research Laboratory, UK.

Schlabbach, Klaus (1997). "Traffic Calming in Europe”, ITE Journal, 67(7), 38-40.

Schermers, G. and P. van Vliet. (2001). "Sustainable Safety - A Preventative Road Safety Strategy for the Future", 2nd ed. AVV Transport Research Centre: Rotterdam, The Netherlands.

Stone, M. (2004). "Adjudication of the Radio 4 Today Programme Speed Tribunal", http://www.ucl.ac.uk/Stats/research/Resrprts/speed.pdf.

Transportation Association of Canada. (1998). "Canadian Guide to Neighborhood Traffic Calming", Transportation Association of Canada, Ottawa, Canada, December.

Transportation Research Board (TRB), (2002). "The Relative Risks of School Travel”, Special Report 269

United Kingdom Department for Transport, (2009). Retrieved 29 June 2009, from ROADACC.STATS@ dft.gsi.gov.uk.

Vis, A.A., Dijkstra, A., and Slop, M. (1992). "Safety effects of $30 \mathrm{~km} / \mathrm{h}$ zones in the Netherlands", Accident Analysis and Prevention 24, 75-86.

Van Schagen, I. (2003). "Traffic Calming Schemes. Opportunities and Implementation Strategies", Report R-2003-22, SWOV. Institute for Road Safety Research, Leidschendam.

Watts G.R. (1973). "Road humps for the control of vehicle speed", TRRL Laboratory Report 597. Transport and Road Research Laboratory, UK.

Webster, D. (1993). "Effect of Traffic Calming Schemes on Vehicle Emissions", Transport Research Laboratory, Crowthorne.

Webster, D.C., Mackie, A.M. (1996). "Review of Traffic Calming Schemes in 20 mph Zones", TRL Report 215. Transport Research Laboratory, Crowthorne.

Webster D.C. (1998). "Traffic calming-public attitude studies: a literature review”, TRL Report 311. Transport Research Laboratory, UK.

Webster D.C., and Layfield R.E. (1998). “Traffic Calming-sinusoidal, „H“ and „S“ humps”, TRL Report 377. Transport Research Laboratory, UK.

Weber P. A., Braaksma J. P. (2000). "Towards a North American Geometric Design Standard for Speed Humps", ITE Journal. 